\title{
KARYA SENI SANGGIT: PERJUMPAAN TRADISI MODERN DALAM PARADIGMA KEKARYAAN SENI RUPA
}

\author{
Dharsono (Sony kartika)
}

\begin{abstract}
The encounter of modern tradition is a paradigm of modern art with a touch of tradition, a phenomenon to search for Indonesian roots in Indonesian cultural identity, then called the work of sanggit. To meet the global era, the alternative we have to build is how to do local studies (traditional arts) that can be an alternative to the development of art towards global ideology, so that global phenomena will become more local. Preservation of traditional art, as a form of cultural resilience. Preservation can be interpreted as preservation and conservation. Preservation is maintaining, caring for, and protecting, while conservation is the preservation of development and / or utilization of value. The purpose of this discussion is to offer a phenomenon of meeting modern traditions in the Indonesian art workforce paradigm; (1) offering the concept of revitalization of sanggit as the basis for art work, (2) offering the concept of reinterpretation of sanggit as the basis for art work and (3) offering the concept of symbolic expression and / or abstraction as the basis of art work. Research / study steps are carried out with a qualitative research model with a cultural approach, referring to the teachings of Javanese culture in accordance with Javanese cultural philosophy and philosophy. This approach emphasizes data interpretation in case specificity. The review of the analysis in this study emphasizes more on the interaction model of qualitative data analysis, using a Javanese cultural approach. Analysis interactions were carried out to analyze qualitative data from the results of empirical data collection. The interactive results of the analysis are then examined by interpretive analysis in a hermeneutic manner.
\end{abstract}

Keywords: encounter modern tradition, revitalization, reinterpretation, symbolic expression

\section{PENDAHULUAN}

Untuk menyongsong era global, maka alternatif yang harus kita bangun adalah bagaimana melakukan studi lokal (seni tradisi) yang mampu menjadi alternatif perkemba- ngan seni rupa menuju ideologi global, sehingga akan terjadi fenomena global akan semakin lokal. Perkembangan seni modern dengan sentuhan seni tradisi nusantara, yang kemudian kita sebut sebagai karya seni sanggit dalam paradigma kekaryaan seni rupa yang Indonesia. Karya seni sanggit merupakan strategi untuk membangun masa depan seni rupa Indonesia yang berkarakter dan beridentitas Indonesia akar Indonesia.
Pembahasan ini menawarkan fenomena perjumpaan tradisi modern dalam paradigma kekaryaan seni rupa Indonesia; (1) menawarkan konsep revitalisasi sanggit sebagai landasan berkarya seni, (2) menawarkan konsep reinterpretasi sanggit sebagai landasan berkarya seni dan (3) menawarkan konsep ekspresi dan/atau abstraksi simbolik sebagai landasan kekaryaan seni.

Pentingnya pelestarian seni tradisi, sebagai bentuk ketahanan budaya. Pelestarian da-pat diartikan sebagai preservasi (preservation) dan konservasi (conservation). Preservasi yaitu menjaga, merawat, dan melindungi, sedangkan konservasi adalah pelestarian pengembangan dan atau pemanfaatan nilai. Konservasi lebih mengu-tamakan perkembangan secara alternatif 
dalam menjawab kondisi seni dan budaya secara global lalu yang kreatif.

\section{DASAR TEORETIS}

Langkah-langkah penelitian/kajian dilaksanakan dengan model penelitian kualitatif dengan pendekatan kebudayaan, mengacu pada ajaran budaya Jawa sesuai dengan filsafat dan falsafah budaya Jawa. Pendekatan ini mene-kankan pada penafsiran data dalam kekhususan kasus (Denzin, 1980:100).

Pengumpulan data menggunakan wawan-cara mendalam (indepth interview), dipilih karena bersifat lentur dan terbuka, dan tidak meng-gunakan struktur yang ketat dan formal, serta bisa dilakukan berulang pada informan yang sama. Pertanyaan yang diajukan bisa semakin terfokus, sehingga informasi yang dikumpulkan semakin rinci dan mendalam. Struktur tersebut dimaksud agar informasi yang diperoleh memiliki kedala-man yang cukup. Kelonggaran cara ini mampu mengorek kejujuran informan dalam membe-rikan informasi yang sebenarnya, teru-tama yang berkaitan dengan perasaan, sikap, dan pandangan mereka terhadap keberadaan artefak seni klasik. Teknik wawancara ini akan dilakukan pada semua informan atau narasumber yang dibutuhkan secara selektif (cuplikan), dengan menggunakan pertimbangan berdasarkan konsep teoretis yang digunakan. Teknik wawancara ini lebih bersifat purposive, yaitu pemilihan infor-man ataupun narasumber berdasarkan criterion based selection (yang dianggap punya kemam-puan yang dapat dipercaya untuk menjadi sumber data), namun demikian informan dan narasumber lain yang dipandang dapat menunjukkan infor-masi yang lebih akurat dan lebih mengetahui permasalahan juga akan dipilih, sehingga pilihan informan dan narasumber dapat berkembang sesuai dengan kebutuhan dan kemantapan dalam perolehan data.

217 | Jurnal Budaya Nusantara Vol. 2 No. 1

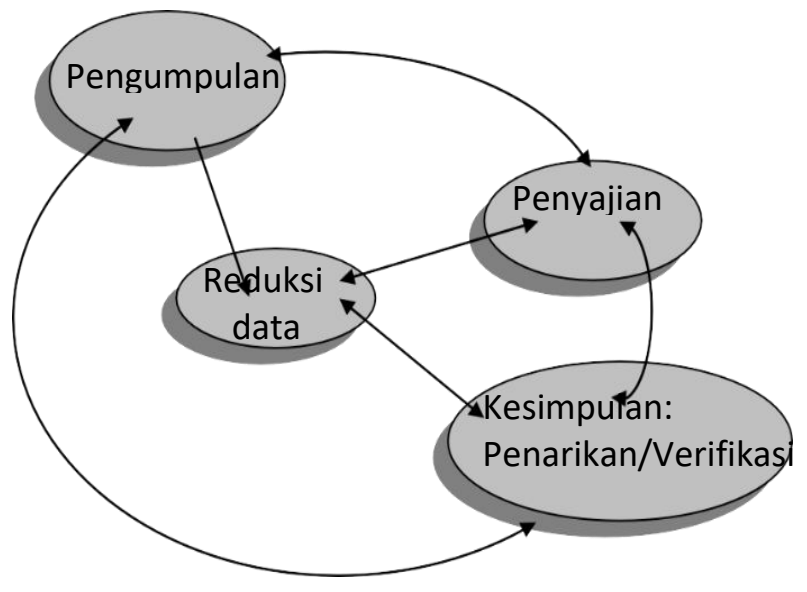

Diagram: Analisis interaktif data kualitatif Model yang digunakan dalam menganalis data kualitatif dengan menerapkan sistem siklus, artinya peneliti selalu bergerak dan menjelajahi objeknya selama proses berlangsung (Rohidi 1992:19-20).

Ulasan yang menyangkut analisis dalam pengkajian ini, lebih menekankan pada model interaksi analisis data kualitatif,dengan menggunakan pendekatan kebudayaan Jawa. Interaksi analisis dilakukan untuk menganalisis data kualitatif hasil pengumpulan data empiris. Untuk mendapatkan hasil yang akurat dari pemilahan secara klasifikasi dan identifikasi. Model ini dipilih karena memungkinkan untuk lebih banyak memberikan satu pencandraan yang mampu menjaring masukan serta paparan dalam rangkuman yang bersifat reduksi data dan penyimpu-lannya. Model yang digunakan dalam menganalis data kualitatif dengan menerapkan sistem siklus, artinya peneliti selalu bergerak dan menjelajahi objeknya selama proses berlangsung (Rohidi, 1992:19-20).

Hasil interaktif analisis tersebut kemudian dikaji dengan interpretatif analisis secara herm-eneutik. Hermeneutik mengarah pada penafsiran ekspresi yang penuh makna dan dilakukan de-ngan sengaja oleh manusia. Melakukan inter-pretasi atas interpretasi yang telah dilakukan oleh pribadi atau kelompok 
manusia terhadap situasi mereka sendiri. Setiap peristiwa atau karya memi-liki makna dari interpretasi para pelaku atau pem-buatnya. Karya yang merupakan hasil interpretasi tersebut selanjutnya menghadapi pembaca atau pengamat dan ditang-kap dengan interpretasi pula. Dalam analisis hermeneutik, peneliti menga-dakan tafsir terhadap karya tersebut seolah karya itu diciptakan kembali sebagai makna baru, sesuai dengan teori kebudayaan yang digunakan (Sutopo, 1996:29). Hermeneutik mengangkat masalah sampai pada apa yang diekspresikan. Oleh karena itu hermeneutik dirumuskan sebagai teori ope-rasi-operasi pemahaman dalam kaitannya dengan interpretasi kebudayaan--sebagai teks. Inter-pres-tasi ditegaskan sebagai pembedaan suatu arti yang tersembunyi di dalam arti yang tampak. Tugas hermeneutik adalah mengenali ihwalnya teks atau dunia teks atau kenyataan yang diba-hasakan oleh teks dan bukan jiwa pencipta (Poespoprod-jo,1991:117-118).

\section{HASIL KAJIAN DAN PEMBAHASAN}

\section{A. HASIL KAJIAN}

Kondisi budaya Indonesia telah mengalami proses transformasi budaya sejak zaman prasejarah. Proses tersebut mencermikan adanya perkembangan budaya etnik (walaupun tidak semua). Adanya perkembangan budaya tersebut, terutama perkembangan sejarah seni rupa Indonesia mempunyai ciri yang menonjol, yang kemudian merupakan cermin keragaman budaya, sebagai salah satu identitas dan jati-diri bangsa Indonesia. Wiyoso (1996), menyatakan bahwa ciri menonjol dari seni rupa Indonesia ialah bentuk yang pluralistis yang tersebar hampir di kawasan Nusantara. Ciri-ciri tersebut mencerminkan kea-nekaragaman kebudayaan suatu bangsa yang mendiami daerah yang terpisah. Tiap daerah me-miliki akar budaya prasejarah sebagai dasar dari tradisi seni rupa Indonesia yang sampai sekarang ada yang masih dipertahankan. Kebu-dayaan hasil tangan terampil bangsa Indonesia dari berbagai macam budaya-seni menurut dae-rahnya masing-masing merupakan modal dasar pembangunan, perlu adanya kajian dan peng- galian sebagai satu usaha pelestarian. Seni tradisi perlu dilestarikan keberadaannya, terutama untuk memberikan satu aset budaya dalam pem-bangunan dewasa ini. Usaha untuk mengenal kesenian Jawa termasuk mencoba untuk menggali latar belakang budaya masyarakat Jawa. Kebu-dayaan Jawa ini mela-hirkan berbagai bentuk seni klasik dalam bentuk karawitan, tari, keris, batik, arsitektur, interior, wayang, dan sebagainya (Wiyoso, 1996:1).

Wiyoso (1993), menyatakan bahwa wayang pada perkembangan Hindu terakhir dengan gaya realistik, sesuai dengan kepentingan agama Hindu dikembangkan oleh keempuan para wali pada zaman Islam dalam rekaan estetik baru sesuai dengan budayaIslam. Kriteria gaya ekspresi wayang mengalami perubahan menjadi non-realistik yang sarat dengan makna perlambangan. Keempuan para Wali dan Raja dalam mengolah unsur rupa wayang; menghasilkan wayang baru yang mengisyaratkan terjadinya proses kesin-ambungan tradisi wayang dilihat dari aspek seni rupa. Kesinambungan tradisi seni memang pernah terputus sehingga perintisan untuk men-capai bentuk kesenian baru terhalang bahkan terhenti sama sekali. Akibat dari kesenjangan, proses perkembangan seni rupa, Indonesia hanya mengharapkan pelestarian tradisi seni semata-mata tanpa upaya pengembangan untuk men-capai tradisi baru. Kesenjangan itulah yang terjadi pada saat lesunya kebudayaan pada masa pemerintahan kolonial Hindia-Belanda, saat keti-ka pamor budaya kerajaan Indonesia-Islam mulai memudar. Di saat itulah kesadaran tradisi bangsa yang terjajah terdesak, hingga berakibat kurangnya daya cipta untuk menemukan bentuk ekspresi baru yang mencerminkan kekuatan tradisi seni ma sa lampau (Wiyoso,1993:41).

Haryoguritno (1993), menyatakan bahwa selain wayang kulit purwa terdapat pula wayang golek purwa yang populer di Jawa Barat (Sunda). Wayang kulit purwa berkembang di Jawa Tengah, Jawa Timur dan Bali. Di Jawa Tengah (Surakarta), perkembangan ini mencapai puncaknya pada kira-kira akhir abad ke XIX. Di

Jurnal Budaya Nusantara Vol. 2 No. 1 | 218 
beberapa daerah lain misalnya Cirebon, Banyumas, Kedu dan Yogyakarta juga terdapat pembuatan dan per-kembangan seni rupa wayang kulit purwa sesuai dengan tingkat kreativitas dan apresiasi keda-erahan masingmasing. Demikian pula, masih ditemukannya sisa-sisa wayang gul-ungan kertas yang terkenal dengan nama Wayang Beber seperti yang terdapat di daerah Wonosari dan Pacitan. Menurut teori yang ada, wayang beber dibuat atau dipertunjukkan untuk pertama kalinya pada za-man Majapahit. Meskipun teori ini dapat dika-takan sudah mapan, namun sejauh ini masih diragukan kebenarannya. Dari hasil perban-dingan dapatlah diketahui bahwa bentukbentuk wayang beber nampak lebih muda dari pada bentuk-bentuk wayang yang seumur dengan zaman Majapahit. Mungkin wayang beber dicip-takan pada masa surutnya kekuasaan Majapahit (awal abad XVI M), sebelum pusat kebudayaan berpindah ke Demak (Jawa Tengah \pm th. 1522 Masehi). Sebagaimana diketahui, pada zaman itu agama Islam mulai diperkenalkan di daerah-da-erah pantai utara pulau Jawa. Akulturasi antara kebudayaan JawaHindu dan Islam berjalan se-cara damai dan kompromistis yang meng-hasil-kan ciptaan wayang baru. Wayang kulit purwa za-man Islam menjadi sedemikian rupa untuk meng-hindari pertentangan dengan dogma ajaran Islam yang tidak membenarkan peng-gambaran manu-sia secara realitis (Haryo-guritno,1993:53-54).

Kartika (2012), berita yang ditulis oleh Ma Huan ( \pm 1414 M), membenarkan adanya wayang beber di Majapahit, tetapi bentuk lukisan dan gaya stilasinya tidak dijelaskan, sehingga mungkin gayanya tidak seperti peninggalan wayang beber dari Pacitan dan Gunung Kidul (Groeneveldt dalam kartika, 2012: 10).

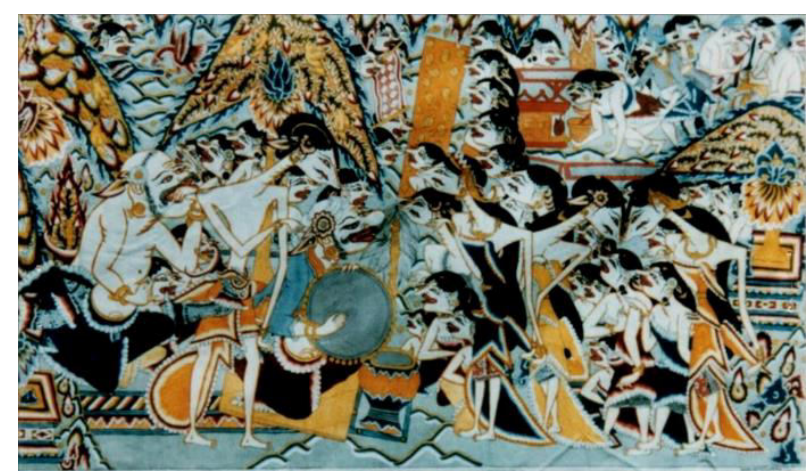

Gambar 1: Wayang beber gaya Pacitan dengan jagong Adegan suasana di Pasar Karangtalun (Photo Bagyo Suharyono), dibuat atas perintah Mangkurat II. Jagong tersebut diambil dari gulungan wayang beber yasan ndalem

Mangkunegaran, yang dilukis dengan Candra sengkala Gawe Srabi Jinawah ing Wong atau tahun 1614 .

Namun apabila ditinjau dari segi bentuk fisik, secara simultan dapat disimpulkan bahwa bentuk pelukisan tokoh-tokoh dalam wayang beber (lihat gambar 1), pasti sudah mengalami penyempurnaan, karena larangan makluk hidup oleh agama Islam, seperti yang tampak pada penggambaran bentuk wajah, leher, atau keseluruhan badannya yang tipis-tipis seperti wayang purwa pada umumnya (Kartika, 2012:10).

Merujuk serat Sastramiruda, wayang beber Pacitan dengan cerita Joko Kembang Kuning dibuat atas perintah Mangkurat II (1677-1678) yang sekarang disimpan oleh keluarga Sarnen Go-nocarita dari desa Karangtalun Kecamatan Do-norejo Kabupaten Pacitan Jawa Timur. Wayang beber Wonosari dengan cerita Remeng Mangu-njaya, dibuat atas perintah Pakubuwana II (1727-1749), yang sekarang disimpan oleh keluarga Sapar Ronosentono dari desa Gelaran Keca-ma-tan Karangmojo Kabu-paten Gunung Kidul (Kartika, 2012:11).

Soedarso (1986), lukisan wayang beber gaya pelukisannya: Wayang beber Pacitan dengan cerita Jaka Kembang Kuning maupun wayang beber Wonosari cerita Remeng Mangunjoyo, ga-ya wayang beber tersebut mempunyai gaya yang non-realistik yang merupakan usaha hasil pere-kaan para empu dan para Wali dalam budaya Islam. Jelas wayang beber tidak dibuat di masa Majapahit, melainkan dari suatu periode ketika pengaruh Islam sudah menjamah seni pewa-ya-ngan di Indonesia. Disinilah perlu digaris-bawahi adanya transformasi budaya Indonesia dalam kesinambungan wayang dalam perkem-bangan seni rupa Indonesia pada periode Hindu dan Islam (Sularto dalam Soedarso, 1986:22). 
Kempers (1959), menjelaskan; (1) Relief Candi Jago lebih dekat dengan bentuk stilasi wayang Bali (dan wayang Jawa pada waktu itu) dari pada relief Ramayana pada Candi Panataran, meskipun Candi Jago lebih tua dari Candi Panataran. Sesuai dengan evolusi bentuk stilasi yang mengilhaminya, mestinya yang diambil sebagai pola adalah perkembangan yang terakhir, (2) Pada Candi Panataran terdapat dua gaya relief, yaitu gaya realistik yang terdapat pada panelpanel relief cerita Kresnayana dan gaya dekoratif mirip wayang yang terdapat pada panel-panel relief Ra-mayana. Jadi nampaknya tidak benarlah ang-gapan umum yang memandang gaya realistik pada relief Prambanan itu kemudian berangsurangsur berubah menjadi dekoratif seperti yang terdapat pada relief di candi-candi Jawa Timur yang lebih muda usianya, (3) Pada relief Candi Jago terdapat kebiasaan untuk membatasi adegan-adegan cerita dengan menggunakan motif gunungan atau kayon seperti yang terdapat dalam pertunjukan wayang kulit. Tentu hal ini meru-pakan pengaruh yang berasal dari pakeliran wa-yang kulit untuk mengawali dan mengakhiri adegan-adegan cerita dengan jalan menancapkan gunungan ditengahlayar. Tanpa pengaruh itu ra-sanya mustahil orang sampai pada penggunaan gunungan atau kayon sebagai pembatas adegan. Sebaliknya ada cara yang lain untuk memberikan tanda batas adegan seperti pada relief Candi Surawana, yaitu dengan penggunaan motif ikal bersambungan dengan arah tegak (Kempers, 1959:84-92). Pendapat B. Kempers tersebut me-mberi gambaran bahwa pertunjukan wayang kulit sudah ada dan bahkan sudah populer dalam masyarakat. Maka mudahlah dimengerti bahwa ketika diperlukan suatu isian untuk menghias dinding-dinding candi, orang lalu sampai pada pilihan untuk mengambil wayang kulit yang populer itu sebagai penghias dinding-dinding candi tersebut. Lagipula banyak cerita pewa-yangan yang cocok sekali dikaitkan dengan pen-dirian sebuah candi seperti misalnya cerita Suda-mala yang merupakan cerita ruwatan, dan ben-tuknya pun serasi dengan bidang-bidang yang akan dihiasinya. Sebagaimana diketahui, dindingdinding candi dipenuhi oleh garis-garis hori- zontal, baik berupa pembagian candi menjadi kepala, badan, dan kaki yang masing-masing masih dibagi-bagi pula, maupun dalam bentuk bingkai-bingkai yang banyak ragamnya itu. Maka bentuk kelir wayang kulit yang memanjang horizontal itu tepat sekali sebagai ide dasar pengisi bidang candi (Kartika, 2012: 14).

Claire Holt(1967), adanya sebuah analog yang menyatakan sudah adanya wayang kulit pada sekitar abad IX-X M sebagai salah satu bentuk wayang tertua, yang ditemukan pada relief candi Prambanan, sebagaimana telah disinggung dalam tulisan Haryonoguritno pada halaman sebe-lum-nya, justru menimbulkan kemungkinan duga-an bahwa sebelum itu prototipe wayang pasti sudah lama ada. Dugaan ini ditunjang oleh ba-nyaknya kata-kata petunjuk pada berbagai piagam yang berasal dari masamasa sebelumnya. Misalnya kata aringgit dalam Piagam Tembaga Jaha (tahun 840 M), disamping kata-kata lain seperti atapukan (pemain topeng), abanyol (pelawak), dll. Demi-kian pula, dalam Piagam Tembaga dari Jawa Te-ngah dijumpai kata-kata macarita dan mawayang dengan cerita Bhimmaya (Holt, 1967:281-282).

Tabrani (1993), proses transformasi budaya terus berlanjut, tidak saja dari perkembangan seni rupa Indonesia Hindu/Budha ke budaya Islam. Wayang kemudian menjadi sumber gagasan dan inspirasi kegiatan seni dari para perupa Indonesia. Sebagai sumber ekspresi tidak hanya ter-batas pada wayang kulit purwa, namun meliputi berbagai jenis wayang; wayang beber, wayang ku-lit, wayang golek, wayang orang, semuanya men-jadi perhatian dan diangkat dari akar tradisi yang dikembangkan secara inovatif yang menghasilkan karya-karya patung, lukis dan kriya. Kurang lebih tahun 1244 telah muncul wayang-gelar, kemudian berkembang apa yang disebut wayang beber $( \pm 1361)$ dan berkembang dengan wayang beber sunggingan $( \pm 1397)$, berlanjut sampai wayang be-ber Cerita Panji ( \pm 1562$)$ dan wayang beber Remeng Mangunjaya ( \pm 1735$)$. Wayang beber se-cara esensi muncul sebagai media seni per-tunjukan. Kemudian, muncul kembali sebagai bentuk salinan (bukan

Jurnal Budaya Nusantara Vol. 2 No. 1 | 220 
sebagai media pertun-jukan) kurang lebih tahun 1939 (Tabrani, 1993:6).

Pendapat tersebut memberi gambaran bahwa adanya satu pergeseran budaya secara esensi, yaitu pergeseran fungsi wayang beber sebagai media seni pertunjukan dan muncul kembali sebagai wayang beber bentuk salinan. Bentuk salinan wayang beber pada perkembangan selanjutnya tidak saja dilukiskan di atas kain, tetapi juga dilukiskan di atas kaca. Salinan wayang beber diatas kain ataupun kanvas kemudian disebut lukis wayang beber. Perkem-bangan terakhir pelukisan wayang (beber atau yang lain) tidak lagi sebagai bentuk salinan tetapi sebagai sumber inspirasi dan media ekspresi. Demikian juga yang terjadi pada wayang kulit (terutama wayang kulit purwa),memang masih bertahan sebagai upaya pelestarian seni tradisi. Namun wayang juga banyak muncul dalam eksistensi dan esensi yang berbeda. Perubahan bentuk dan gaya tampak pada karya seni yang mendambakan kebebasan pribadi. Kebebasan untuk mengekpresikan lewat interpretasi baru dari sosok wayang yang ia jadikan landasan dalam proses penciptaan oleh senirupawan Indonesia. Wayang kemudian menjadi acuan seniman; sebagai sumber inspirasi dan media ekspresi (Kartika, 2012:15).

Kartika (2012), transformasi budaya kemudian bergulir, dan para perupa mulai melihat dan memanfaatkan wayang sebagai media penciptaan seni, sekaligus dalam usaha pe- lestarian seni tradisi maupun inovasi secara kreatif. Pemanfaatan wayang sebagai sum- ber gagasan dalam cipta seni oleh pelukis modern semakin semarak. Maka muncullah berbagai corak dan gaya seni lukis wayang pada perjalanan seni lukis Indonesia. Kehidupan budaya diha-dapkan pada dua keku-atan pandangan, yaitu pandangan konservatif dan progresif. Pandangan konsevatif menghendaki adanya orientasi pada upaya melestarikan warisan budaya secara utuh, usaha untuk merentangkan benang emas yang mampu menghubungkan bu-daya masa lalu dengan masa kini. Di lain pihak, pandangan progresif menghendaki adanya sebu-ah perubahan melalui proses modernisasi. Dua kekuatan tersebut berjalan seiring dan memberi kemung-kinan 221 | Jurnal Budaya Nusantara Vol. 2 No. 1 adanya saling bergesekan, yang akan mengakibatkan adanya bentuk kesenian yang berorentasi kepada kedua pandangan ter-sebut. Kemudian muncullah karya hasil revi-taliasi, yang merupakan karya studi-klasik dalam konsep garap kini, dan karya hasil reinterpretasi karyakarya yang memanfaatkan idiom seni tradisi sebagai sumber gagasan penciptaan seni modern. Model tersebut kemudian menjadi mode pengembangan seni tradisi Indonesia sebagai satu ke-senian modern dengan akar tradisi. Seni tradisi yang demikian itu kemudian disebut seni tradisi kini. Seni tradisi kini maupun seni modern, secara konseptual sama-sama berlandaskan pada krea-tivitas. Tingkat kreativitas tergantung dari kem-ampuan seniman yang profesional di bidangnya, dan mampu menangkap serta menyelami berba-gai masalah, sekaligus mampu menjadi anak zam-annya. Wujud dan arah perkembangan seni tradisi dewasa ini dapat bergerak dari berbagai arah mulai dari tradisi dalam inovasi kreatif; yaitu menggunakan konsep tradisi secara kreatif dengan per-bendaharaan tradisi yang sudah melewati fase hayati sampai ke pada bentuk yang kreatif dalam nafas tradisi masa kini (Karti-ka,2012:52).

Kusnadi (1977), hadirnya kesenian dalam masyarakat Indonesia sekarang ini, seniman dalam kedudukannya sebagai pembentuk gaya dalam penciptaan karya seni, tercermin pada citra budaya serta corak kepribadian bangsa. Guna me-mperoleh citra budaya Indonesia, karya seni lukis Indonesia terwujud dalam berbagai tema melalui pengolahan gaya lama atau baru ke dalam media seni lukis. Pada tahap permulaan, seniman In-donesia melukiskan segala sesuatu sesuai dengan wujudnya yang nampak atau keseluruhan keha-dirannya bercorak realistis. Perkembangan selan-jutnya melalui pengintisarian bentuk dan rasa, juga penciptaan lewat stilasi bentuk atau pengo-lahan terhadap bentuk dan iramanya, peng-kristalisir ide-ide simbolis dan menjadikan sim-bol-simbol tersebut sebagai lambang pada seni lukis. Penggunaan unsur garis dan warna dalam penciptaan bentuk secara murni sebagai dasar penciptaan seni lukis para seniman Indonesia 
(Kusnadi, 1977: 146). Perjalanan seni lukis modern Indonesia sampai munculnya berbagai corak dan ragam gaya akibat perkembangan pola pikir kaum akademis dewasa ini. Karya-karya seniman akademis dengan berbagai ragam ekperimen alte-rnatif, senantiasa berjalan berdampingan dengan karya-karya non akademis yang bercorak konve-nsional, masing-masing memberikan fenomena dan sodoran alternatif yang mewarnai perjalanan seni lukis Indonesia dewasa ini. Secara kontek-stual per-kembangan munculnya seni lukis waya-ng bukan secara langsung dipengaruhi oleh ragam dan gaya pada masa atau periode tertentu dalam perjalanan seni lukis Indonesia. Namun secara konseptual ada hubungan yang tidak langsung an-tara ragam gaya pada seni lukis wayang di In-donesia dengan perkembangan pola pikir yang terjadi dalam perjalanan seni lukis Indonesia. Ha-dirnya kesenian dalam masyarakat Indonesia se-karang ini, seniman dalam kedudukannya sebagai pembentuk gaya dalam penciptaan karya seni, tercermin citra budaya serta corak kepribadian bangsa. Guna memperoleh citra budaya Indonesia, karya seni lukis Indonesia terwujud berbagai tema melalui pengolahan gaya lama atau baru ke dalam media seni lukis. Pada tahap permulaan seniman Indonesia melukiskan segala sesuatu sesuai dengan wujudnya yang nampak atau keseluruhan kehadirannya bercorak realistis. Perkembangan selanjutnya melalui pengintisarian bentuk dan rasa, juga penciptaan lewat stilasi bentuk atau pengolahan terhadap bentuk dan iramanya, pengkristalisir ide-ide simbolis dan menjadikan simbol-simbol tersebut sebagai lambang pada seni lukis. Penggunaan unsur garis dan warna dal-am penciptaan bentuk secara murni sebagai dasar penciptaan seni lukis para seni- man Indonesia (Kusnadi, 1977: 146). Pelukis Agus Jaya pada masa Persagi dan Revolusi, Kusnadi dalam pene-litiannya tentang sejarah seni rupa Indonesia, mengatakan: Karya seni dengan komposisi figur yang ditata secara dekoratif, mengajak kita untuk menghargai keindahan lewat alam secara deko-ratif dan melalui warna serta kesan monumental dari komposisi figurfigurnya. Suasana mistik yang digambarkan lewat karyanya, sama kuatnya dengan rasa sensualitas dari tokoh/figur wanit-anya. Penggam- baran figur pada karya Agus Dja-ya diilhami dari tokoh pewayangan dan relief can-di (Kusnadi, 1977: 165). Sudjojono, dalam kum-pulan tulisannya yang berjudul Seni Lukis, Kes-enian dan Seniman memberikan pertimbangan dan pengarahan seninya, sehingga mampu me-njadi panutan generasinya saat itu. Dinyatakan bahwa setiap seni- man yang harus dilakukan per-tamatama adalah harus berwatak seniman pula. Keberanian melontarkan ide pada dunia, walaupun tidak mendapat tanggapan publik sekalipun. Dengan watak demikian, ia akan berani mem-perjuangkan apa yang dinamakan kebenaran dan mencintai apa yang diyakini sebagai keindahan. Keindahan dalam arti estetik menurut seniman, bukan menurut publik. Karya seni diciptakan ha-nya atas dorongan dari dalam dan memaksa sen-iman untuk melahirkan (Kusnadi, 1977:169).

Dharsono (1999), Masa Persagi dan Revolusi (1937-1945) di Indonesia, ialah saat dimana aspirasi kebangsaan sangat kuat tumbuh di setiap dada orang Indonesia. Masa untuk menaikkan harkat martabat bangsa dan mengenyahkan pen-jajah. Lahirnya Persatuan Ahli Gambar Indonesia (PERSAGI) (1937), sebenarnya merupakan mata rantai dari lahirnya Budi Utomo (1908), lahirnya Pendidikan Taman Nasional (1922), Sumpah Pe-muda (1928) serta lahirnya Pujangga Baru yang bercita-cita tentang sastra baru Indonesia. Persagi bertujuan mengembangkan seni lukis di kalangan bangsa Indonesia, dengan mencari corak Indo-nesia baru. Sudjojono dan pelukis di jamannya, sudah mulai dipengaruhi oleh adanya aspirasi pribadi yang bertolak dari lingkungan budaya; yaitu kekuatan budaya tradisi wayang ataupun motifmotif ukir yang terdapat pada rumah tradisional. Di samping itu, pernyataan di atas juga megisyaratkan bahwa pelukis pada masa itu sudah banyak dipengaruhi oleh tema dan teknik pelu-kisan modern (barat). Ini menunjukkan mun-culnya bentuk dan gaya pelukisan modern Indo- nesia akar Indonesia (Dharsono,1999:5354). 
Sanento Yuliman (1990) dalam diskusi memberi catatan; sedikitnya ada dua masa yang perlu dicatat dalam kurun waktu terakhir ini. Ma-sa pertama yaitu Gerakan seni rupa baru di mana kebebasan kreatif mengalami puncak idealisme dari seniman-seniman muda yang merasa dituntut oleh pertumbuhan zaman dan gelombang situasi. Gerakan seni rupa baru muncul seputar tahun 1970-an, merupakan peristiwa kesenilukisan yang perlu mendapat catatan tersendiri. Masa kedua adalah isu globalisasi seni lukis pasca tahun 1980, dimana para seniman dihadapkan pada satu ken-yataan ekonomi dunia atau dengan kata lain se-niman milik konglomerat. Masa ini sering disebut Boom Seni Lukis Indonesia. Seluruh masa itu ditandai oleh peningkatan jumlah lukisan yang diper-jualbelikan dan sangat laku. Terbukti ada pening-katan jumlah dan frekwensi pameran, pertum-buhan galeri komersial, pertumbuhan sponsor pameran dan bertambahnya kolektor lukisan. Di samping itu nampak bertambahnya pelukis yang terlibat, peningkatan harga lukisan, perluasan tempat-tempat pameran tidak hanya diselenggarakan di tempat-tempat tertentu, tetapi juga di hotel, bank dan pusat-pusat perbelanjaan. Gejala lain seperti pelelangan lukisan, pemalsuan lukisan, beredarnya kembali lukisan lama dan kuno (Yuliman,1990:1-2).

I.W. Suarta, (1993) memberi gambaran perjalanan seni lukis di Bali. Bali \pm 1930 - 1970-an timbul perkembangan baru dalam seni lukis setelah hadirnya pelukis R. Bonet, Walter Spies dan Cokorde Agung Sukawati melalui badan Pita Ma-ha. Di antara seniman Bali Baru tersebut yang memilih tema wayang antara lain; I.G. Nyoman Lempad, Anak Agung Gede Mregeg, Gusti Ketut Kobot, Gusti Molog, Ida Bagus Made, Ida Bagus Rai. Seniman lukis wayang mengadakan peru-ba-han fisik karya dalam berkarya; dinamis, ana-tomis, memperhatikan perspektif, komposisi ya-ng tak terlalu padat dengan pewarnaan yang lebih bervariasi. Selanjutnya karya-karya tersebut dise-but dengan Seni Lukis Wayang Bali modern gaya Pita Maha (I.W. Suarta, 1993:14-15).

223 | Jurnal Budaya Nusantara Vol. 2 No. 1
Lukisan gaya Pita Maha, mengambil tema wayang sebagai sumber inspirasi seniman dalam berkarya. Bentuk wayang tergambar jelas, terma-suk teknik pelukisan wayang yang telah menam-pilkan kesan anatomi plastis. Pergeseran tematik ialah dari tema yang diambil dari kitab Sutasoma dan dari kitab keagamaan beralih ke tema kes-eharian. Keserderhanaan warna, pertim-bangan komposisi dipengaruhi konsep estetika modern lewat R. Bonet dan Walter Spies. Namun kedua pelukis tersebut masih tetap menggunakan teknik pewarnaan, gaya pelukisan secara tradisi yang khas. Konsepsi estetik barat masih dalam batas tertentu yaitu; pada anatomi dan perubahan tema yang diangkat. Namun demikian bahwa lukisan wayang modern tersebut tampak adanya inovasiinovasi yang perlu dicatat sebagai satu loncatan perkembangan seni lukis modern Bali (Kartika2012:49).

Hadirnya pelukis R. Bonnet, Walter Spies dan Cokorde Agung Sukawati, mampu mengu-bah gaya lukisan Bali tradisional gaya wayang pa-da sebagian pelukis di Bali, menjadi gaya lukisan Bali yang menampilkan kesan realistis dengan ko-mposisi yang disederhanakan. Peng-gunaan war-na primer, meningkat ke warna-warna campuran dalam menghasilkan sebuah karya lukis gaya Pita Maha. Pada dasarnya gaya seni lukis Pita Maha memiliki dasar, yang dapat memper-temukan dua dasar estetika tradisional Bali dipadukan dengan estetika modern arahan Bonnet, dengan memper-hatikan realisme fisik untuk mengungkapkan ke-hidupan sehari-hari masyarakat Bali, tanpa meni-nggalkan citra seni lukis Bali Tradisional (Kusna-di, 1977:162).

\section{B. PEMBAHASAN}

Perjumpaan tradisi modern merupakan paradigma seni modern dengan sentuhan tradisi, merupakan fenomena untuk mencari identitas budaya Indonesia akar Indonesia, kemudian disebut karya sanggit. Untuk menyongsong era glo-bal, maka yang tak dapat ditawar adalah bagaimana menguasai modern dengan sentuhan tra- 
disi, sesuai dengan pandangan masyarakatnya. Wawasan terhadap paradigma seni modern harus kita tingkatkan, artinya seni modern mestinya ti-dak sekedar dipelajari, tetapi bagaimana mengu-asai konsepsi modern sebagai sarana untuk mem-pelajari tradisi masa lalu. Hasilnya akan mampu memberikan fenomena baru yang mampu mem-bingkai dinamika kehidupan seni modern yang mampu menjawab persoalan dalam mencari in-dentitas budaya Indonesia. Sehingga desainer dan atau seniman Indonesia tidak hanya jadi tukang di negeri sendiri saja, tetapi harus mampu mene-mukan jati diri bangsa dan tampil sebagai seniman dan atau desainer yang mampu menampilkan citra Indonesia akar Indonesia yang berwawasan modern. Artinya untuk menghadapi global bukan berarti mempelajari, tetapi menguasai teori uni-versal dari pendidikan seni/desain modern (bar-at) saja, kalau tidak mau dikatakan sebagai sen-iman atau desainer modern kecil atau barat-barat kecil. Menghadapi global harus mampu mene-mukan jati-dirinya sendiri sebagai manusia Indo-nesia (bagaimana mengu-asai modern dengan se-ntuhan tradisi). Ini sesuai dengan paradigma baru pendidikan tinggi seni di Indonesia yakni: meng-gali, mengkaji dan mengo-lah potensi pluralitas budaya lokal sebagai modal agar mampu bersaing dalam percaturan global. Untuk menghadapi glo-bal maka harus studi lokal, semakin global sema-kin lokal (Kartika,2016:85).

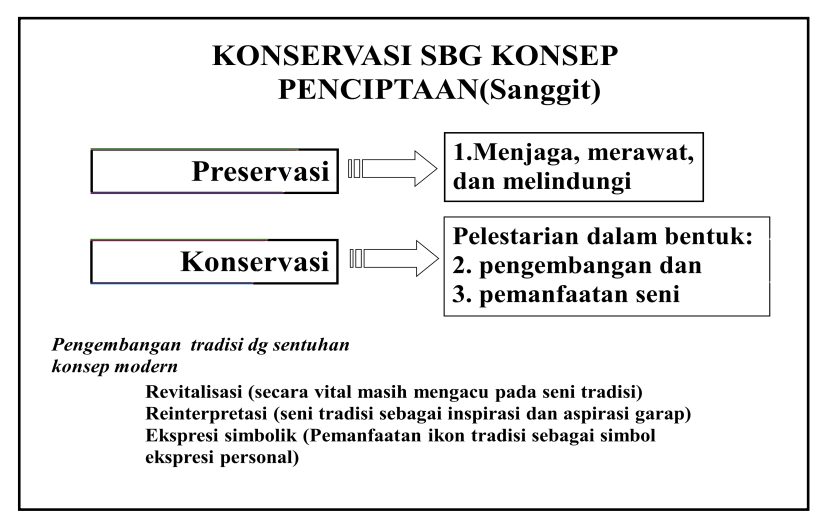

\section{Konsep RevitalisasiSanggit}

Revitalisasi merupakan karya seni sanggit sebagai bentuk reproduksi dengan inovasi garap,
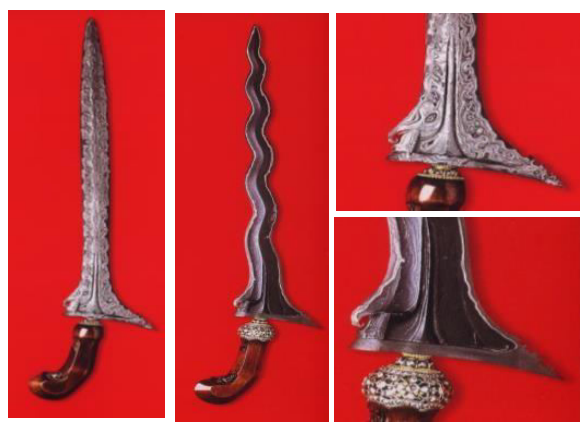

merupakan karya sanggit dengan konsep revitali-sasi. Karya sanggit tersebut mempunyai tingkat kepentingan yang mengacu pada bentuk

pelestarian seni tradisi, dengan mencoba memberikan alternatif karya-karya dengan teknik reproduksi inovasi garap. Secara teknis mengalami reduksi pengolahan lewat unsur-unsur; garis kontur, teknik pewarnaan dan sajian isian bidang serta rekayasa tematik cerita. Karya yang dibuat merupakan karya studi-tradisi dalam usaha untuk mencari alternatif pelestarian, dengan mencoba menghadirkan kembali atau meniru karya peninggalan (warisan) budaya masa lalu. Seni revitalisasi secara vital masih mengacu seni tradisi seba-gaiacuan pokoknya. Sehingga strategi penciptaan sebagai konsep berkarya adalah dengan menggu-nakan konsep konservasi atau pelestarian dengan cara mutrani (nunggak semi), yaitu meniru sesuai pakem, tetapi pengolahan teknik dan bahan ses-uai dengan kebutuhan saat ini. (Dharsono 201-7:58)

Gambar 2: Keris luk tangguh kasunanan Surakarta Hadiningrat, pasikutan-nya demes (serasi, menyenangkan, tampan, enak dilihat)

(Haryono Guritno, 2006:358, repro scan.

Bamban Yuwono 2010). Revitalisasi sanggit merupakan karya tiruan dari sumbernya yaitu karya keris yang dibuat pada saat pemerintatahan

Kasunana Surakarta hadiningrat, orang Jawa menyebut dengan istilah mutrani atau nunggak semi)

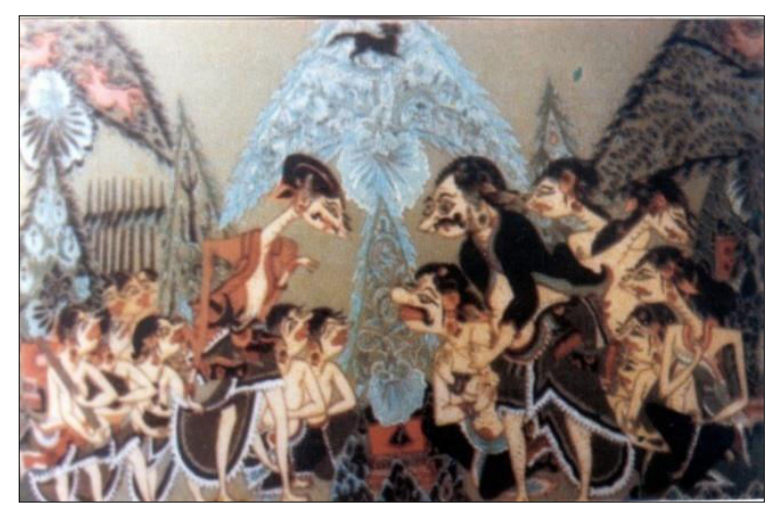


Gambar 3: Sumadi (1993), Pertemuan Panji Asmara bangun dengan para pengawalnya: seni

lukis wayang beber di atas kaca, yang dilukis secara konsep revitalisasi, (Repro photo Kartika 1985) Lukisan Wayang beber yang dilukis di atas tersebut secara revitalisasi (secara vital), mengacu padaseni tradisi (wayang beber Pacitan) dengan garap medium. Pelukisan kembali wayang beber dengan media cat minyak di atas kaca, menggambarkan: Pertemuan Panji Asmara Bangun dengan para pengawalnya, yang dilukis dengan konsep revitalisasi dengan gaya dekoratif reproduksi inovasi.Sosok wayang dan isiannya sudah mengalami inovasi garap medium, dan mengalami penyempurnaan teknis pelukisan pada sosok wayang, reduksi isian, dan perubahan dari teknik pewarnaan sungging tradisi ke garap teknik gradasi warna

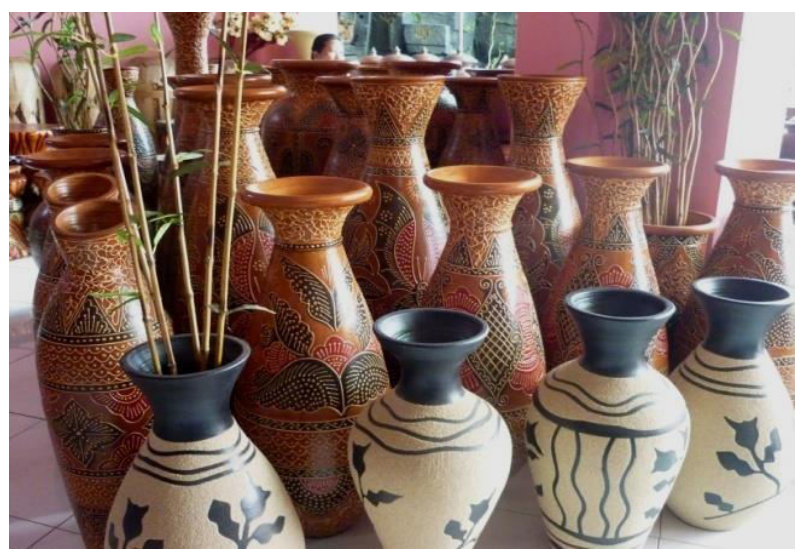

Gambar 4: "Gerabah Betek", karya industri keramik yang digeluti para perajin di wilayah

Dinoyo, Kota Malang, Jawa Timur (wordpress.com, unduh Kartika 2018)Karyakarya gerabah di atas dibuat secara revitalisasi, secara vital mengacu pada seni tradisi (gerabah tradisi) dengan garap medium dan penambahan esesoris atau hiasan goresan dan warna.

\section{Konsep Reinterpretasi Sanggit}

Bentuk karya sanggit memanfaatkan tema cerita, dengan menggunakan konsep reinterpre-tasi simbolik. Pemanfaatan cerita merupakan su-mber gagasan (ide) dan pemanfaatan idiom tradisi secara struktur mengacu pada teknik seni mo-dern. Dalam kata lain seniman

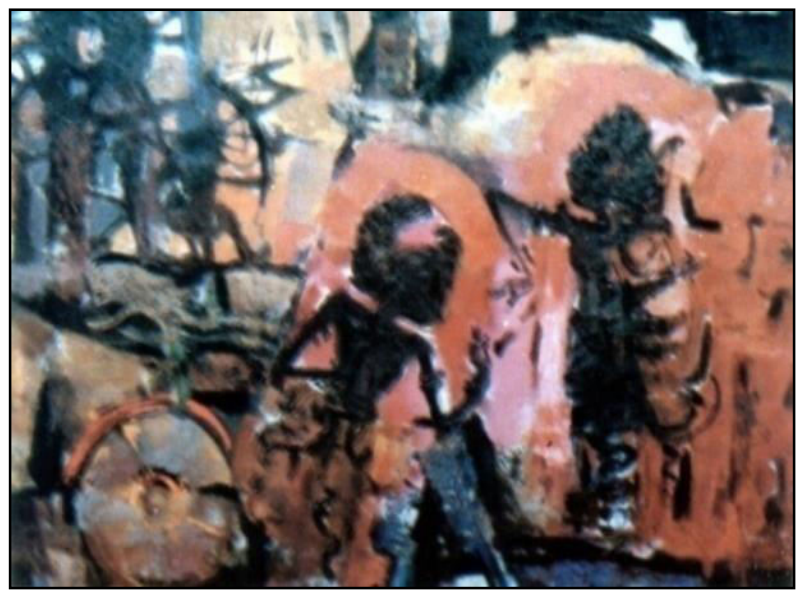

yang tergolong dalam kelompok ini mencoba meng-gambarkan idiom tradisi secara ekpresif dalam bingkai kreasi tematikIdiom-idiom tradisi hasil reinterpretasi, merupakan struktur paduan dengan mengguna-kan teknik pembabaran modern, maka akan ter-jadi berbagai versi gaya sesuai hasil reduksi pen-golahan senimannya. Walaupun kar-ya-karya ters-ebut melukiskan satu rekayasa kreasi tertentu, na-mun ide kreasi merupakan hasil ungkapan pera-saan seniman (Kartika, 2016:90, Dharsono 201-7:59 ).

\section{Gambar 5: Made Sudibia (1993), Dialog di \\ Padang Kurusetra, cat minyak di atas kanvas, ukuran 110 X 90cm. (Photo repro Kartika 2015).}

Lukisan di atas secara tematik melukiskan wayang cerita Mahabharata dalam adegan Dialog antara Arjuna dengan Krisna (Wisnu) di Padang Kurusetra, yang dilukiskan secara ekspresif dalam komposisi figuratif, dari dua sosok wayang Arj-una dan Krisna (sebagai Dewa Wisnu) terlukis secara dekoratif ekspresionis gaya seni lukis kon-temporer Bali. Pelukisan tersebut secara konsepsi merupakan bentuk reinterpretasi seni lukis seba-gai perwujudan rekayasa seniman dalam mengungkapkan gagasannya. Komposisi yang dibangun secara keseluruhan seolah merupakan kompo-sisi gaya Bali kontemporer, namun inspirasi yang diusung seniman tentang pengadegan antara Ar-una dan Dewa Wisnu masih tertangkap, artinya inspirasi atau ide penciptaan 
merupakan aspirasi garap dalam seni lukis reinterpretasi dalam este-tika sanggit. (Kartika, 2012:107)
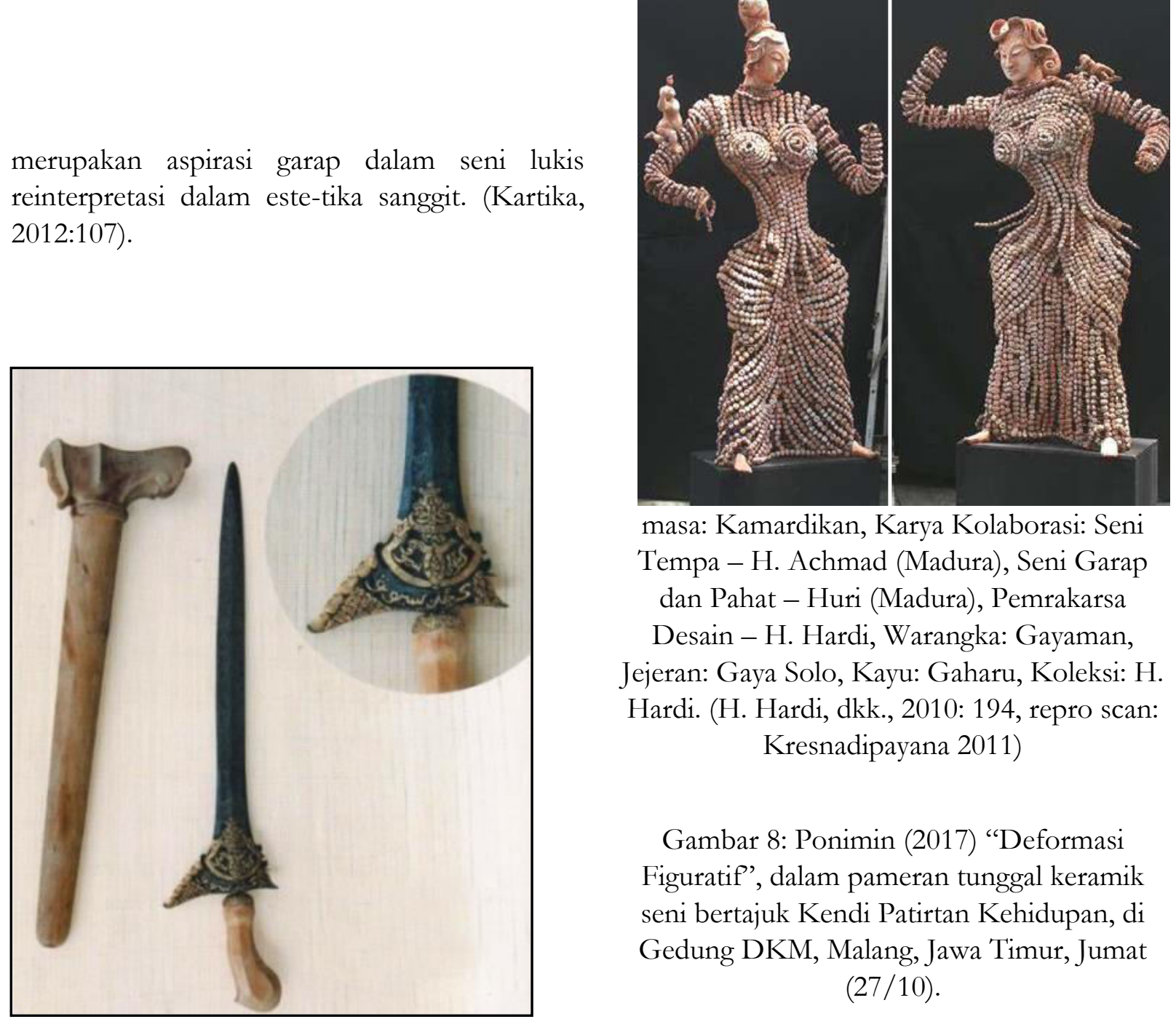

masa: Kamardikan, Karya Kolaborasi: Seni Tempa - H. Achmad (Madura), Seni Garap dan Pahat - Huri (Madura), Pemrakarsa

Desain - H. Hardi, Warangka: Gayaman, Jejeran: Gaya Solo, Kayu: Gaharu, Koleksi: H. Hardi. (H. Hardi, dkk., 2010: 194, repro scan: Kresnadipayana 2011)

Gambar 8: Ponimin (2017) "Deformasi Figuratif', dalam pameran tunggal keramik seni bertajuk Kendi Patirtan Kehidupan, di Gedung DKM, Malang, Jawa Timur, Jumat $(27 / 10)$.

Gambar 6 kiri : Keris lurus dapur Mangkurat, tinatah kamarogan, warongko sandang walikat, masa kamardikan, jejeran kayu kemuning, Koleksi Basyir M.Barnawi. (H. Hardi, dkk., 2010: 135, reproscan: Kresnadipayana 2011)

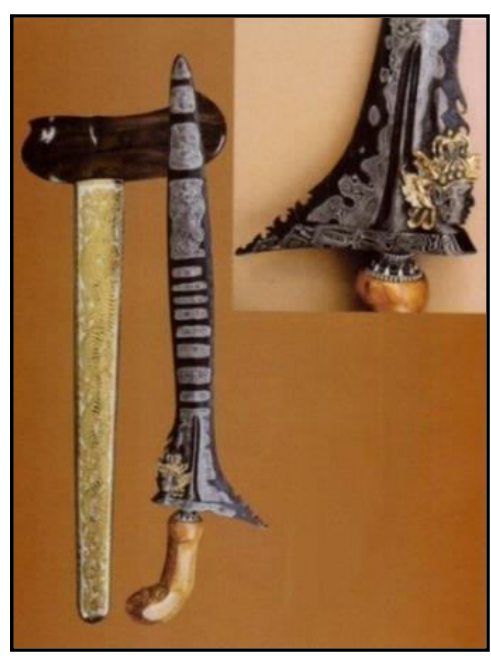

Gambar 7 kanan: Kanjeng Kyai Yudhoyono, Dhapur: Panji Nom, Pamor: Samudra Sabar,

Karya-karya keramik di atas merapakan penggambaran figur manusia dengan konsep reinterpretasi. Secara konsepsi digarap secara konsep reinterpretasi sanggit yaitu paduan antara id-iom tradisi dengan teknik pembabaran modern, maka akan terjadi berbagai versi gaya sesuai hasil reduksi pengolahan senimannya. Walaupun kar-ya karya tersebut melukiskan satu rekayasa kreasi tertentu, namun ide kreasi merupakan hasil ung-kapan perasaan seniman.

\section{Abstraksi/Ekspresi Simbolik}

Karya sanggit bentuk abstraksi simbolik, secara konsepsi merupakan bentuk seni modern dengan memanfaatkan idiom tradisi sebagai elemen dasar penyusunannya. Pemanfaatan idiom tersebut secara kontekstual telah mengalami reduksi karena adanya proses pengolahan seni-man dalam menafsirkan bentuk secara simbolik. Hadirnya idiom tradisi tidak lagi sebagai penu-angan ide secara tematik tetapi sebagai simbol tekstual yang disodorkan seniman, untuk mem-berikan 
kebebasan tafsir (Kartika, 2016:113, Dharsono-

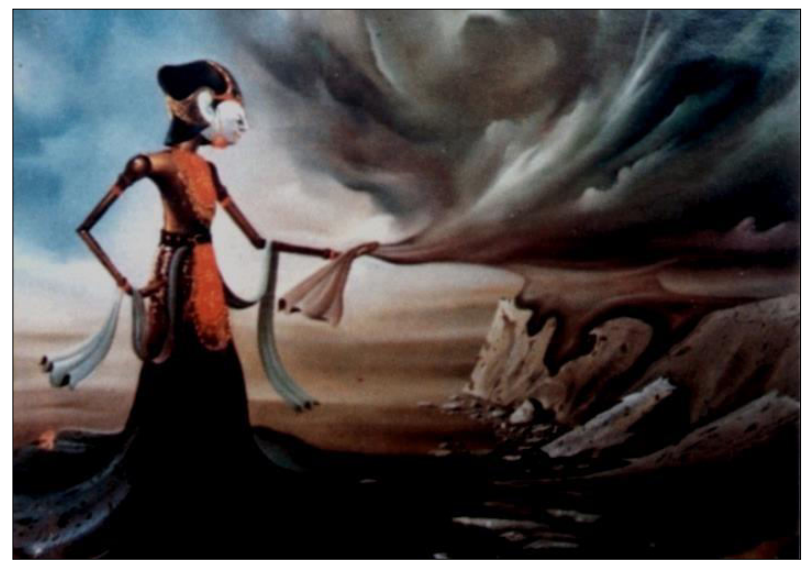

,2017:61)

Gambar 9 : Ivan Hariyanto (1993), Mengibas

Awan cat minyak di atas kanvas, ukuran 90X70 cm , (Photo repro Sony Kartika 1998)

Lukisan karya Ivan Hariyanto, menggunakan simbol wayang sebagai medium untuk me-ngungkapkan perasaan senimannya. Pelukis me-nggunakan simbol interpretatif, dari sosok wa-yang golek dalam posisi mengibas awan yang dilukis dengan gaya surealisme. Secara konseptual merupakan ekspresi simbolik (abstraksi sim-bo-lik). Hadirnya sosok Harjuna pada lukisan Ivan Haryanto, tidak lagi sebagai penuangan ide secara tematik tetapi sebagai simbol tekstual yang dis-odorkan seniman, untuk memberikan kebe-basan tafsir. (Kartika, 2012: 131, Dharsono 2016: 116).

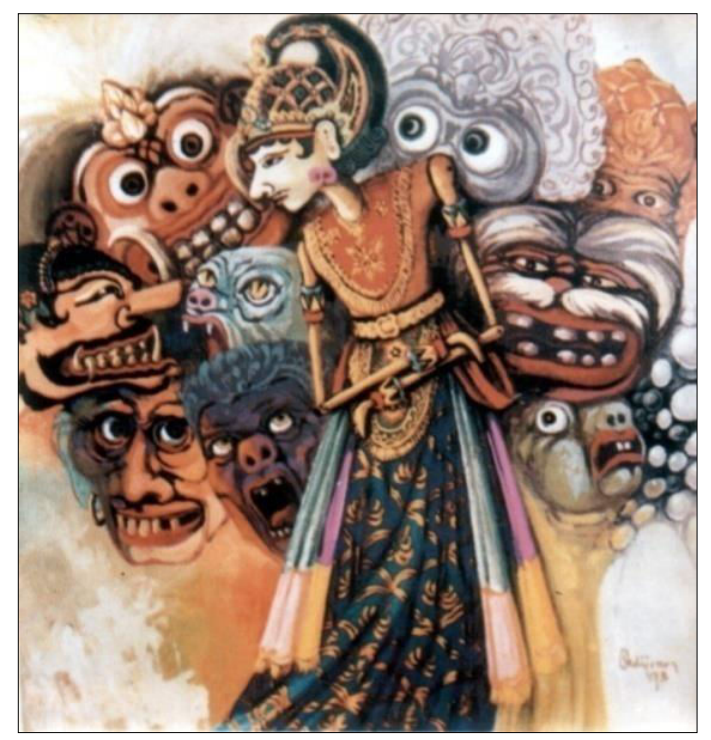

227 | Jurnal Budaya Nusantara Vol. 2 No. 1
Gambar 10: Oedijono (1993), Cobaan, akrelik di atas kanvas, ukuran 100 X 100 cm, (Repro Sony Kartika, 1998).

Oedijono menggunakan simbol wayang sebagai medium untuk mengungkapkan perasaan senimannya. Seni Lukis wayang bentuk abstraksi simbolik, secara konsepsi merupakan bentuk seni lukis modern dengan memanfaatkan sosok waya-ng golek purwa Harjuna sebagai elemen dasar pe-nyusunan. Pelukis meminjam idiom tradisi sosok Raden Arjuna yang dilukis lewat wayang golek dikelilingi oleh topengtopeng. Secara konseptual merupakan ekspresi simbolik (abstraksi simbo-lik). Pemanfaatan tokoh Harjuna secara kon-tekstual telah mengalami reduksi karena adanya proses pengolahan seniman dalam menafsirkan bentuk wayang secara simbolik. Hadirnya sosok Harjuna tidak lagi sebagai penuangan ide secara tematik tetapi sebagai sim-bol tekstual yang diso-dorkan seniman, untuk memberikan kebebasan tafsir (Kartika, 2012:147; Dharsono 2017:61).

\section{KESIMPULAN}

Menghadapi global harus mampu menemukan jati-dirinya sendiri sebagai manusia Indonesia (bagaimana menguasai modern dengan sen-tuhan tradisi). Ini sesuai dengan paradigma baru pendidikan tinggi seni di Indonesia yakni: meng-gali, mengkaji dan mengolah potensi pluralitas budaya lokal sebagai modal agar mampu bersaing dalam percaturan global. Untuk menghadapi glo-bal maka harus studi lokal, semakin global sem-akin lokal. Kini budaya lama itu diminati kembali sebagai salah satu alternatif pengembangan seni Pembahasan ini dapat disim-pulkan bahwa per-kembangan seni tradisi dengan sentuhan modern, yang kemudian disebut este-tika sanggit dalam paradigma kekaryaan seni lukis, yaitu

1. Fenomena yang muncul sebagai karya revitalisasi simbolik.Seni revitalisasi secara vital masih mengacu seni tradisi sebagai acuan pokok-nya. Sehingga strategi penciptaan sebagai konsep berkarya adalah dengan menggunakan konsep konservasi atau pelestarian dengan 
caramutrani (nunggak semi), yaitu meniru sesuai pakem, tetapi pengolahan teknik dan bahan sesuai dengan kebutuhan saatini

2. Fenomena yang muncul sebagai karya reinterpretasi simbolik. idiom-idiom tradisi hasil reinterpretasi, merupakan struktur paduan dengan menggunakan teknik pembabaran modern, maka akan terjadi berbagai versi gaya sesuai hasil reduksi pengolahan senimannya. Walaupun karya-karya tersebut melukiskan satu rekayasa cerita tertentu, namun ide cerita tersebut hanya merupakan hasil rangsang ungkapan perasaanseniman

3. Fenomena yang muncul sebagai karya abstraksi dan/atau ekspresi simbolik.Idiom tradi-si yang dilukiskan bukan lagi mewakili idiom tertentu tetapi sebagai satu bentuk simbolisme kehidupan.Seniman berusaha mengungkapkan lewat idiom sebagai salah satu simbol yang diin-formasikan seniman terhadappenghayatnya.

\section{DAFTAR PUSTAKA}

Dharsono (Sony Kartika)

2007 Estetika. Bandung: Rekayasa Sains.

"Sanggit (Version) Aesthetics", The meeting of modernity and tradition in the work paradigm of the art of painting" Artikel Ilmiah International Institute for Science, Technology and Education, All rights reserved. You are receiving this email because you are an author of an IISTEjournal

The Liang Gie

1976 Garis Besar Filsafat Keindahan. Yogyakarta: Penerbit karya. Langer, Sussane. (1953). Feeling and Form: A Theory of Art. New York: Charles Scribnes. Myers, Bernard S. (1967). Art and Civilization. New York: Mac Grawhill Book Company.

Kartika, Dharsono Sony

2016 Kreasi Artistik, perjumpaan tradisi modern dalam paradigma kekaryaan seni, Su-rakarta: LPKBN Citra Sain
2012 Seni Lukis Wayang, Surakarta: ISIPress

Parker, de Witt.H.

1946 The Principles of Aesthetics. New York: Appleton Century Crafts. Pepper, Stephen C. (tth). Principles of Art Appreciation. New York: Brece and Company.

Primadi.

1978 Proses Kreasi Appresiasi Belajar.Bandung: ITB.

Read, Herbert

1959 The Meaning of Art. New York: Pinguin Book. 